\title{
Business Intelligence Applied to The Consumption of lodinated Contrast Agents in Computed Tomography Scans
}

JOSE RODRIGO ANDRADE ( $\sim$ joser@ufcspa.edu.br)

UNIVERSIDADE FEDERAL DE CIÊNCIAS DA SAÚDE DE PORTO ALEGRE

Luciano Blomberg

UNIVERSIDADE FEDERAL DE CIÊNCIAS DA SAÚDE DE PORTO ALEGRE

\section{Research Article}

Keywords: business intelligence, radiology, diagnostic imaging, contrast media

Posted Date: March 18th, 2021

DOI: https://doi.org/10.21203/rs.3.rs-154518/v1

License: (c) (i) This work is licensed under a Creative Commons Attribution 4.0 International License.

Read Full License

Version of Record: A version of this preprint was published at BMC Medical Informatics and Decision Making on March 25th, 2022. See the published version at https://doi.org/10.1186/s12911-022-01814-9. 


\section{Abstract}

Background: The management of the use of iodinated contrast agents (ICA) in the computed tomography (CT) has clinical and financial impacts; however, the approaches in the current research setting have limitations with regard to their exploration of the theme. This work describes the application of the stages of a process of business intelligence (BI), from the formulation of business questions, the building of a research database, and the adaptation of a multidimensional model, to the creation of dashboards to give support to the decision-making process in a hospital. This research aims to apply and document a BI process that provides support to the decision making of managers, so the use of ICA can be better managed, allowing for the identification of situations in which the material was wasted using a study applied to the hospital field.

Methods: An applied exploratory research with a quantitative approach in a database made up by 24 variables and 35,388 records extracted from the RIS (Radiology Information System) that is used by the General Hospital of Porto Alegre - HCPA. The software used, supplied by AGFA Healthcare, were the Qdoc system (version 6.2.0) and the Impax BI (Version 11.1.1) for, respectively, data entry and data exploration. At the end of the process, a total of 48 variables was considered.

Results: The BI process applied allowed for the identification of situations in which ICA was being wasted during the operationalization of the volume/mass ratio of the agent injected in the patient. It also offered the necessary substantiation for the managers to formulate plans, actions, and controls associated to the use of the material. This work made it possible to diminish in $15.65 \%$ the total consumption of ICA injected in the patients who underwent the CTAB1 exam (full CT scan of the abdomen), with a projected economy of US\$10,039.95, for the performance of this exam from 2020 on. The measuring of the impact and the relevance of the process was $99.6 \%$ positive, according to the evaluation of the managers.

Conclusions: This research generated clinical and financial benefits for the HCPA, a positive evaluation by the managers and the generation of new knowledge, which can be shared with other public or private health organizations.

\section{Introduction}

In Brazil, in 2019, a budget of US\$ 23.62 billion was destined for the area of actions in health, according to the transparency portal of the Brazilian General Comptroller's Office[1]. The HCPA, for instance, is a public, general, and teaching hospital which spends approximately US\$280 million per year to maintain its operation. A recent analysis, provided by the Radiology Service of the HCPA through the management information system (MIS) shows a consumption of materials that reaches US\$190 thousand per year in the CT unit. $70 \%$ of this direct cost expense is represented by the consumption of ICA.

Currently, in the HCPA, the control of the use of materials is carried out by the Storeroom Service, which restocks the material used in each day in the local storage of the Imaging Services. This type of 
volumetric control of daily use does not allow for a complete managing of the use of the ICA in the CT, nor does it allow for its optimization.

Despite currently having computerized flow systems, the HCPA still requires better tools to support decision making that show its managers, in a fast and safe manner, whether the processes using ICA in the CT are adequate or need to be reviewed and/or improved and/or optimized. In this logic, a better management in the use of the ICA can generate gains from two essential perspectives: one of them related to the clinical effects of the ICA injection (e.g.: nephrotoxicity, fluid overload) [2-4] and another one about the financial point of view with regard to the use of resources.

Previous researches showed that the application of $\mathrm{BI}$ in radiology has been generating significant gains to businesses, although new studies on the ICA are still needed. In one of the studies conducted, Nagy et al. (2009) described improvements in the waiting time of patients and in the time to issue the results through the application of a BI process which was shown to be significant to aid in the making of more efficient decisions to improve productivity, performance, and the quality in the department. In 2010, Prevedello et al. presented the steps took to create the model-prototype of a BI data repository, showing how it was used to start an investigation of the viability of using new specific KPIs in Radiology. In the same year, the theme "diagnostic time and inspection time" was chosen and discussed by authors Liu, Yu and Li (2010), who built a model to analyze the factors that influenced the number of people attended, the waiting time for the diagnostic and the inspection times for the Radiology sector in three aspects: days of the week, hours, and professional category [5-7].

Another relevant study about the applicability of BI in Radiology was published in 2016, when the authors Jones et al. projected, developed, and implemented the prototype of a BI tool to evaluate the mismatch between capacity and demand. After the BI was analyzed, they carried out a qualitative assessment through interviews with the main interested parties, which reported gains with regard to the ease of information access. More recently, Moriarity, Sigler e Morrison (2020) reported the construction of a DW in a private Radiology clinic. This approach was elaborated from the point of view of investments in IT and in the team. The authors presented practical applications of analysis and of reports provided to all departments of the organization in the last 5 years, including finances, IT, human resources, billing, coding, clinical operations, and juridical operations. Furthermore, they state that reliable data now inform the aspects of organizational decision making in daily operations, growth, strategic planning, and efficiency [8-9].

The objective of this research is to apply and document a BI process that provides support to the decision making of managers, so the use of ICA can be better managed, allowing for the identification of situations in which this material was wasted in CT exams in the General Hospital of Porto Alegre.

\section{Methods}

The nature of the tasks involved indicates that the type of research carried out was mainly exploratory. The approach was quantitative, based on the evaluation of the results by the managers and business 
analysts. The field of application is that of data analysis and support to decision making in the areas of Radiology and Imaging Diagnostics.

The BI process described in this research was structured in three groups of activity, related to:

1. Interests of the managers: the set of activities used to identify the business questions relevant for the organization;

2. Applied technologies: the group of activities involving the use of technologies and strategies for ETL, multidimensional modeling, and the generation of information from a set of data from transactional systems of the organization;

3. Discoveries and conclusions: this was the set of activities related to the evaluation and interpretation of data to give support to decision making. The conclusions are obtained in the final activity, from the evaluation of the managers about the process applied.

Interest of the Managers

Initially, the survey about the interests of the managers was carried out, and business questions about consuming ICA in the CT scan were defined. To guide the investigation, a semi-directed interview was elaborated, based on the methodology of Marconi and Lakatos (2010) [10], as a way to elucidate the assistance process and document managerial needs. This instrument, structured in an investigative method made up by seven items, included the evaluation of 16 business questions related to ICA consumption. At the end of the process, it was possible to identify more relevant variables and metrics, and a choice was made to formulate a new business question, more closely related to the interests manifested by the interviewee, which guided the development of this work.

Applied Technologies

The selection of interest variables from operational source system was the first activity carried out to seek answers to the formalized business question. The operational source system adopted was the RIS, from the company AGFA Healthcare, through the software Qdoc (version 6.2.0), which uses $11 \mathrm{~g}$ Oracle databases, destined to transactional processing (OLTP). This system is employed in the care flow of patients who need to undergo radiology exams in the HCPA, and was the main data source for the selection of the 24 variables of interest, related to the consumption of ICA.

The ETL of the Qdoc for the multidimensional DW model of Impax BI refers to the activity of extracting, transforming, and loading the transactional database into the analytical base. To do so, the Impax BI tool (Version 11.1.1), by AGFA Healthcare, was used. It also adopts Oracle $11 \mathrm{~g}$ databases, but is dedicated to analytical processing (OLAP). Among the 31 models available at the DW, the multidimensional requestprocedure model was selected, from the subject field of attention provided. This model of Impax BI had already mapped 23 out of the 24 variables of interest selected using the Qdoc. Therefore, an additional variable, which the model lacked, was mapped, and incorporated to the daily routine of ETL. 
The multidimensional model was adapted in the DW of the Impax $\mathrm{BI}$, as was the generation of the data cube. This activity consisted in the selection of an additional set of variables of interest that already existed in the Impax $\mathrm{Bl}$, in addition to the creation of variables derived from measures calculated in the requisition-procedure model. Considering this new selection, a final set of 48 variables was determined. Filters were applied for the generation of the data cube at Impax BI and the later application of the OLAP. The cube contained 35,388 valid records. It was formed using data about the care provided to 18-year-old or older patients who underwent CT scans using ICA in a 24-month period.

The construction of an investigative dashboard for the use of OLAP operations was a technical activity developed under the permanent advice of the managers, seeking points of view that could facilitate data interpretation. Four charts were created, which were independent, though complementary, in a data dashboard for the iterative manipulation in real response time. The investigative dashboard was conceived to allow one to perform OLAP operations such as slice, dice, drill-dawn, and roll-up, which were applied to the data cube.

Discoveries and conclusions

Through the consumption and manipulation of data in the investigative dashboard, we sought to answer the business question through managerial analysis, together with the managers. OLAP operations were used in ad hoc investigations, seeking to uncover undesirable events. Considering broader settings, there was an attempt to gradually increase the level of granularity, discussing increasingly specific settings and comparing them to different perspectives with regard to process standardization.

Planning, actions and controls were defined through evidences and results, allowing interested parties to create operational tactics based on the evidence surveyed to plan and act. The BI process continued in the organization after a possibility of improving the standardization of operational processes was found, which involved the definition of an ICA volume for the injection of each patient. A set of changes was applied, mobilizing the interested parties. Two control reports were structured, allowing data to be monitored and enabling comparisons of the scenario in the different stages of the process applied. The changes could be accompanied by the managers through the data sent weekly by the controls generated. To do so, a resource of the Impax Bl agent was used, a tool that makes it possible, through its configurations, to automate the sending of reports within a pre-established time frame of interest. Finally, the clinical and financial impacts could be shown and analyzed.

The evaluation of the perception of managers about the applied BI process was carried out at the end of the work, with the HCPA management. To do so, a new semi-directed interview was carried out, based on the methodology of Marconi and Lakatos (2010), seeking to quantify the impact and the relevance of the process from the perspective of the interviewee. The results are presented in quantitative form, considering the percentage of the mean of the individual results.

\section{Results}


This work aimed to apply a BI process in the routine of a large hospital to better manage the consumption of ICA, which is the material with the highest direct expense cost in the CT scan unit. The main interest of managers and business analysts was to search for an opportunity to lower costs, increasing the competitiveness of the organization in the market and generating the greatest possible benefit to the patient.

Survey of the interests of the managers and a definition of business questions about the consumption of ICA in CT scans.

At first, a set of business questions was defined empirically, regarding the evaluation of the ICA volume consumed per scan, and the ratio of volume injected to patient mass. The objective was to identify opportunities to improve assistance processes and reduce expenses of material consumption in the CT scans.

The business questions formulated at first were structured and evaluated through a consultation with the managers of the areas of management, medicine, administration, radiological techniques, and nursing, through a semi-directed interview based on the methodology of Marconi and Lakatos (2010). From this point onwards, we formulated a new business question, more closely related to the interests manifested by the interviewees. As a result, this work was based on the following business question: in which situations is it possible to identify the waste caused by the use of excessive materials?

To better understand the analysis, one must consider:

1) Approach to answer the business question:

a) identifying, in the attention to patients who undergo CT exams with the use of ICA the relations and dependences between (I) the volumes injected and (II) the ratio of volume injected to patient mass, with other variables.

2) Information generated:

a) injected volume, in $\mathrm{mL}$;

b) ratio of injected volume to patient in $\mathrm{mL} / \mathrm{Kg}$;

considered by:

the patient (patient, mass group, age group, age, mass, and sex);

exam (specialty, part of the body, name of the exam);

exam request (request, origin of the attention);

exam room (exam room, equipment); 
radiology technician (name of the radiology technician);

nursing technician (name of the nursing technician);

injection (injection flow, type of injection);

material (concentration, cost, batch);

adverse event (extravasation, volume of extravasation, reaction);

date (date, year, semester, trimester, month, day, day of the week;

time (time, hour, shift).

3) Importance of the information:

a) identifying whether there is a pattern of volume and of volume/mass injected per exam and its dependences, to evidence and investigate situations in which there are signs of material being wasted.

This approach allowed the structuring of data to carry out analysis of the information from different perspectives or dimensions.

Selection of variables of interest from operational source system

To answer the business question, a search was carried out in the Qdoc for a set of variables that could describe attention with the involvement of ICA injections during CT scans in patients. At first, 24 variables correlated to the care and the consumption of ICA were selected. These were already part of the care flow, and their data was filled in in the Qdoc system.

Figures 2 and 3 present the variables of interest of the operacional source system from two perspectives, respectively: form of existence (native or created) and form of input (automatic or manual). Some of these variables are native to the Qdoc system, that is, they exist as a standard inside the software; others were created in the system, by request of the Radiology Service. They were customized to attend to the specific assistance and managerial needs of the institution. Figure 2 shows, in a flowchart, the 24 variables selected from the Qdoc system, highlighting that 15 were native, while 9 were created.

Another criteria to distinguish between the variables is related to the form in which the data is input. It can be automatic, through the integration between the HIS and RIS systems, or manual, through the input of users. As Figure 3 shows, the data input in the Qdoc system is partly automated, through the process of integration with the hospital system. This takes place when the attention of a new patient starts, which means that a set of data previously registered at the HIS gets transfered to the RIS without the need of filling it in again. A set of 12 variables of interest is inputted in this manner. The other 12 variables depend on the manual input of the Nursing team, as part of the care during the performance of the exam.

ETL of the Qdoc for the multidimensional model of the Impax BI DW 
After the variables of interest were found in the Qdoc system, a multidimensional model of the Impax BI DW was searched, one that could be adapted and used for the objectives of this work. The Impax BI is a market good developed to attend, globally, to the health organizations in the field of Radiology. The AGFA Healthcare company, a multinational in the RIS and PACS industry, adapts Oracle BI, from the Oracle Corporation, developing some multidimensional models and ETL services in its OLTP (RIS and PACS) services for the DW (Oracle).

The request-procedure model was chosen for use in this work since it has a direct correlation with the care effectively offered, since, in the HCPA flow, the requisition of the exam of the patient is sent to the Qdoc system at the moment the patient arrives for its performance.

The Impax BI allows for adaptations, with the mapping of new variables into the preexisting multidimensional models, a service that the AGFA, its supplier, provides. The client is responsible for requesting new mappings according to the interests of the business.

Therefore, from the 24 variables of interest in the Qdoc, 15 had a native mapping for the Impax $\mathrm{Bl}$, while 8 were later mapped by request of the organization. Later, the mapping of the variable "mass" was requested, to a total of 9 variables created and considered in the development of this work. It is important to highlight that the new mappings carried out ( 9 in total) were made viable because of an agreement with the provider of Impax BI, which included the possible addition of up to 15 variables ( 5 text, 5 number, and 5 boolean variables).

The process of extraction, transformation, and the loading of data from operational database (Qdoc) to the analytical database (Impax $\mathrm{BI})$ is pre-programmed to take place every $24 \mathrm{~h}$, always starting at 12:01 a.m., every day. This inputs all models created with the data generated in the $24 \mathrm{~h}$ of the previous day.

Adaptation of a multidimensional model in the Impax BI DW and generation of the data cube

The multidimensional request-procedure model, available in the Impax BI DW and associated to the field of attention to patients who undergo Radiology exams was adapted to answer to the business question. The first adaptation was the incorporation of the variable of interest patient mass, created in the Qdoc, in the ETL routine, and its mapping in the multidimensional request-procedure model. Therefore, the values filled in to the Qdoc during the attention of the patient started to be extracted from the operational database and to be loaded into the analytical database. With that, as presented in the 1st Quadrant of Table 1, the 24 variables of interest were complete in the same analytical environment.

Since this is a preexisting model, a set of complementary variables of interest, available for use, was developed, according to what is presented in the 2 nd quadrant of Table 1 . This set of variables is part of those that already existed in the model and was selected to facilitate the analyses.

The second adaptation necessary was the creation, within the multidimensional request-procedure model, of secondary variables and calculated measures. This set of variables, created within the multidimensional model, was selected for use and adaptation and is in the 3rd quadrant of Table 1. For a 
better perception of the adaptations carried out in the model during the development of the work, the lines of the table related to them are highlighted in a dark tone.

Table 1 Set of variables used in the multidimensional request-procedure model with a description of the variable and of its type of existence in the model 


\begin{tabular}{|c|c|c|c|c|}
\hline Set & $\begin{array}{l}\text { Variable } \\
\text { ID }\end{array}$ & $\begin{array}{l}\text { Name of the } \\
\text { variable }\end{array}$ & Description of the variable & $\begin{array}{l}\text { Type of } \\
\text { existence } \\
\text { in the } \\
\text { model }\end{array}$ \\
\hline \multirow{14}{*}{$\begin{array}{l}\text { 1st quadrant: } \\
\text { Native and created } \\
\text { variables of } \\
\text { interest generated } \\
\text { by the transaction } \\
\text { system and } \\
\text { imported into the } \\
\text { model }\end{array}$} & 1 & Date & $\begin{array}{l}\text { Date in which the patient was } \\
\text { cared for }\end{array}$ & NM \\
\hline & 2 & Time & $\begin{array}{l}\text { Time in which the attention took } \\
\text { place }\end{array}$ & NM \\
\hline & 3 & Age (years) & $\begin{array}{l}\text { Age of the patient at the day of the } \\
\text { attention }\end{array}$ & NM \\
\hline & 4 & Sex & Sex of the patient & NM \\
\hline & 5 & Patient mass & $\begin{array}{l}\text { Mass of the patient at the day of } \\
\text { the attention }\end{array}$ & $\mathrm{CP}$ \\
\hline & 6 & $\begin{array}{l}\text { Name of the } \\
\text { exam }\end{array}$ & Name of the exam & NM \\
\hline & 7 & Part of the body & Part of the body analyzed & NM \\
\hline & 8 & Modality & $\begin{array}{l}\text { Diagnostic modality (CT scan, } \\
\text { magnetic resonance imaging, X- } \\
\text { ray, ultrasound scan, etc.) }\end{array}$ & NM \\
\hline & 9 & $\begin{array}{l}\text { Origin of } \\
\text { attention }\end{array}$ & $\begin{array}{l}\text { Classification of the origin of the } \\
\text { attention (outpatient clinic, } \\
\text { hospitalization, emergency, } \\
\text { external) }\end{array}$ & NM \\
\hline & 10 & $\begin{array}{l}\text { Clinical } \\
\text { information }\end{array}$ & $\begin{array}{l}\text { Information described by the } \\
\text { physician requesting the exam, } \\
\text { together with the request and } \\
\text { including relevant information on } \\
\text { the clinical issues of the patient } \\
\text { and the reason why the exam was } \\
\text { requested. It accompanies a set of } \\
\text { answers to questions of interest of } \\
\text { the radiologist, which aim to aid in } \\
\text { the medical diagnostic. }\end{array}$ & NM \\
\hline & 11 & Exam room & $\begin{array}{l}\text { Room in which the exam was } \\
\text { conducted (room 1, room 2, room } \\
3 \text {, all rooms) }\end{array}$ & NM \\
\hline & 12 & $\begin{array}{l}\text { ICA } \\
\text { concentration } \\
\text { (mg iodine/mL) }\end{array}$ & $\begin{array}{l}\text { ICA concentration }(300 \mathrm{mg} \\
\text { iodine/mL, } 350 \mathrm{mg} \text { iodine } / \mathrm{mL} \text {, all } \\
\text { concentrations) }\end{array}$ & $\mathrm{CO}$ \\
\hline & 13 & Batch number & Number of the batch of the ICA & $\mathrm{CO}$ \\
\hline & 14 & $\begin{array}{l}\text { Form of ICA } \\
\text { injection }\end{array}$ & $\begin{array}{l}\text { Manner in which the ICA was } \\
\text { injected (automated with an } \\
\text { injector pump, manual with a } \\
\text { syringe, all manners) }\end{array}$ & $\mathrm{CO}$ \\
\hline
\end{tabular}




\begin{tabular}{|c|c|c|c|}
\hline 15 & $\begin{array}{l}\text { Injection flow of } \\
\text { ICA }(\mathrm{mL} / \mathrm{s})\end{array}$ & $\begin{array}{l}\text { Injection flow of the ICA through } \\
\text { an endovenous pathway. }\end{array}$ & $\mathrm{CO}$ \\
\hline 16 & $\begin{array}{l}\text { Occurrence of } \\
\text { adverse } \\
\text { reactions }\end{array}$ & Occurrence of adverse reactions & $\mathrm{CO}$ \\
\hline 17 & $\begin{array}{l}\text { Occurrence of } \\
\text { extravasation }\end{array}$ & Occurrence of extravasation & $\mathrm{CO}$ \\
\hline 18 & $\begin{array}{l}\text { Amount of } \\
\text { extravasation }\end{array}$ & Amount of extravasation & $\mathrm{CO}$ \\
\hline 19 & Pacient_code & $\begin{array}{l}\text { Sequential number of the attention } \\
\text { within the RIS system }\end{array}$ & NM \\
\hline 20 & Request_code & $\begin{array}{l}\text { Sequential number in the HIS } \\
\text { system of exam requests }\end{array}$ & NM \\
\hline 21 & Exam_code & Identification code of the exam & NM \\
\hline 22 & $\begin{array}{l}\text { Radiology } \\
\text { Technician_code }\end{array}$ & $\begin{array}{l}\text { Identification code of the } \\
\text { Radiology technician }\end{array}$ & NM \\
\hline \multirow[t]{2}{*}{23} & Nursing & \multirow{2}{*}{$\begin{array}{l}\text { Identification code of the Nursing } \\
\text { technician }\end{array}$} & \multirow[t]{2}{*}{ NM } \\
\hline & Technician_code & & \\
\hline 24 & ICA volume $(\mathrm{mL})$ & $\begin{array}{l}\text { Records of the volume of ICA } \\
\text { injected in the patient }\end{array}$ & $\mathrm{CO}$ \\
\hline 25 & Year & Year in which attention took place & EM \\
\hline 26 & Month & $\begin{array}{l}\text { Name of the month in which } \\
\text { attention took place }\end{array}$ & EM \\
\hline 27 & Day & $\begin{array}{l}\text { Number of the day in which the } \\
\text { attention took place }\end{array}$ & EM \\
\hline 28 & Weekday & $\begin{array}{l}\text { Weekday in which the attention } \\
\text { took place }\end{array}$ & EM \\
\hline 29 & Semester & $\begin{array}{l}\text { Name of the semester in which } \\
\text { attention took place }\end{array}$ & EM \\
\hline 30 & Trimester & $\begin{array}{l}\text { Name of the trimester in which } \\
\text { attention took place }\end{array}$ & EM \\
\hline 31 & Hour & $\begin{array}{l}\text { Hour in which the attention took } \\
\text { place }\end{array}$ & EM \\
\hline 32 & Equipment & $\begin{array}{l}\text { Equipment used to carry out the } \\
\text { exam, including a description of } \\
\text { the producer and number of } \\
\text { channels (Ge } 8 \text { channels, Phillips - } \\
16 \text { channels, Toshiba - } 64 \\
\text { channels, all) }\end{array}$ & EM \\
\hline 33 & Name of the & Name of the Radiology technician & EM \\
\hline
\end{tabular}




\begin{tabular}{|c|c|c|c|c|}
\hline & & \multirow{2}{*}{$\begin{array}{l}\text { Radiology } \\
\text { technician } \\
\text { Name of the } \\
\text { Nursing } \\
\text { technician }\end{array}$} & \multicolumn{2}{|l|}{ that carried out the attention } \\
\hline & 34 & & $\begin{array}{l}\text { Name of the Nursing technician } \\
\text { that carried out the attention }\end{array}$ & EM \\
\hline & 35 & No. of exams & Measure - sum of exams & EM \\
\hline \multirow{13}{*}{$\begin{array}{l}\text { 3rd quadrant: } \\
\text { secondary } \\
\text { variables and } \\
\text { measurements } \\
\text { calculated and } \\
\text { created in the } \\
\text { model }\end{array}$} & 36 & Shift & $\begin{array}{l}\text { Work shift (morning }-7: 00 \text { a.m. to } \\
\text { 12:59 p.m, afternoon - 1:00 p.m. } \\
\text { to } 6: 59 \text { p.m, Night - 7:00 p.m to } \\
\text { 6:59 a.m., all) }\end{array}$ & $\mathrm{CM}$ \\
\hline & 37 & Age group & $\begin{array}{l}\text { Age group of the patient at the day } \\
\text { of the attention }\end{array}$ & $\mathrm{CM}$ \\
\hline & 38 & Mass range & $\begin{array}{l}\text { Mass range of the patient at the } \\
\text { day of the attention }\end{array}$ & $\mathrm{CM}$ \\
\hline & 39 & Specialty & $\begin{array}{l}\text { Medical specialty of radiological } \\
\text { diagnostic }\end{array}$ & $\mathrm{CM}$ \\
\hline & 40 & Exam group & $\begin{array}{l}\text { Group of the exam (tomography or } \\
\text { angiotomography) }\end{array}$ & $\mathrm{CM}$ \\
\hline & 41 & Cost $(\mathrm{R} \$ / \mathrm{mL})$ & $\begin{array}{l}\text { Ratio of financial value to ICA } \\
\text { volume }\end{array}$ & $\mathrm{MC}$ \\
\hline & 42 & $\begin{array}{l}\text { Volume per } \\
\text { mass }(\mathrm{mL} / \mathrm{Kg})\end{array}$ & $\begin{array}{l}\text { Ratio of the volume of ICA injected } \\
\text { in the patient to the mass of the } \\
\text { patient }\end{array}$ & $\mathrm{MC}$ \\
\hline & 43 & $\begin{array}{l}\text { Reference } \\
\text { values for } \\
\text { volume }(\mathrm{mL})\end{array}$ & $\begin{array}{l}\text { Reference values for the volume of } \\
\text { ICA to be injected for each } \\
\text { combination of exam and weight } \\
\text { range of the patient }\end{array}$ & $\mathrm{MC}$ \\
\hline & 44 & Excess $(\mathrm{mL})$ & $\begin{array}{l}\text { Volume of ICA injected above the } \\
\text { volume limit }\end{array}$ & $\mathrm{MC}$ \\
\hline & 45 & $\begin{array}{l}\text { Cost of the } \\
\text { excess (R\$) }\end{array}$ & $\begin{array}{l}\text { Cost of the volume of ICA injected } \\
\text { above the volume limit }\end{array}$ & $\mathrm{MC}$ \\
\hline & 46 & $\begin{array}{l}\text { Rate of } \\
\text { contrasted } \\
\text { patients (\%) }\end{array}$ & Rate of variable 47 to variable 35 & $\mathrm{MC}$ \\
\hline & 47 & $\begin{array}{l}\text { No. of } \\
\text { contrasted } \\
\text { exams }\end{array}$ & $\begin{array}{l}\text { Sum of the exams where variable } \\
12 \text { was filled in }\end{array}$ & $\mathrm{MC}$ \\
\hline & 48 & $\begin{array}{l}\text { Maximum } \\
\text { volume per } \\
\text { exam } \\
\text { (mL/exam) }\end{array}$ & $\begin{array}{l}\text { Ratio of the sum of the volume of } \\
\text { ICA injected in the patient to the } \\
\text { sum of the exams carried out }\end{array}$ & $\mathrm{MC}$ \\
\hline
\end{tabular}


Captions: Acronyms correspond to the form of existence in the multidimensional request-procedure model: NM - native Qdoc variable that previously existed in the model; CO - variable created in the Qdoc and imported into the model by request of the organization; CP - variable created at the Qdoc and imported to into the model at the request of the researchers; EM - variable that already existed in the model; CM - secondary variable created in the model by the researchers; MC - measure calculated and created in the model by the researchers.

It should be highlighted that the data considered for the development of this work was generated starting in the 1st of July, 2017. The generation of the data cube from the adapted multidimensional requestprocedure model was carried out through the application of the following set of filters:
a) period from $07 / 01 / 2017$ to $06 / 30 / 2019$;
b) age of the patient equal or above 18 years of age;
c) the modality is CT;

d) ICA concentration: is equal to the concentration of $300 \mathrm{mg}$ iodine $/ \mathrm{mL}$ or $350 \mathrm{mg}$ iodine $/ \mathrm{mL}$, that is, the records indicate the use of ICA in the concentrations of interest;

e) ICA volume: is not null, that is, the volume of ICA used is filled in;

f) ICA volume/mass of the patient: is not null, that is, the ratio of the volume of ICA injected to the mass of the patient is a valid value;

g) ICA injection flow: is not null, that is, the injection flow of the ICA used is filled in;

h) Mass of the patient: is lower than $300 \mathrm{~kg}$, that is, extremely high values, possible results of mistyping of the ICA volume, are excluded;

i) Mass of the patient: is higher than $20 \mathrm{~kg}$, that is, extremely low values, possible results of mistyping of the ICA volume, are excluded;

The cube formed by the filters applied was made up by 35,388 records.

Construction of an investigative dashboard for the use of OLAP operations

The multidimensional model chosen and the data cube generated lead to a series of viable analyses. Considering the study of situations in which there was waste due to the excessive use of the material, an investigative dashboard was created. It is made up of four charts, making it possible to simultaneously explore all of its variables, forming any desired combination of analysis in real time.

The proposal of the investigative dashboard consolidates four charts that have their presentations altered simultaneously according to the selection, made by the users, of the filters applied to the 
variables. This structuring is aimed to allow OLAP operations using the data set, enabling slice, dice, drilldawn, and roll-up procedures.

To facilitate these operations in the OLAP cube, a prompt was created, that is, a system component which is a command area for the selection of data, which was made available in the dashboard, with the charts. The prompt allows the user to perform ad hoc explorations according to their interest, applying the same set of selections to all dashboard charts. Figure 4 presents the final dashboard generated, which brings in its wake an investigative proposal which can be adopted by other CT services.

Consumption and manipulation of data in the investigative dashboard

There was a significant discovery after multiple investigations through ad hoc exploration, starting from the selection of filters in the prompt of the investigative dashboard. This approach considered six perspectives and evaluated varied settings of patient attention. The set of possible combinations explored in this data cube can be noted in Table 2.

Many combinations were tested, always starting from the most general scenario possible and moving towards the most specific one. Figure 5 presents the ratio of the volume to patient mass within a general scenario of the Radiology Service, considering only the year 2018 and the month of June.

Table 2 Analysis of the data cube from six perspectives 


\begin{tabular}{|c|c|}
\hline Perspectives & Selection options \\
\hline \multirow[t]{5}{*}{ When? } & Year: $2017,2018,2019$, ou all \\
\hline & Semester: 1 st, $2 \mathrm{nd}$, or all \\
\hline & Trimester: 1 st, $2 \mathrm{nd}, 3 \mathrm{rd}, 4$ th, or all \\
\hline & Month: free choice of month, or all \\
\hline & $\begin{array}{l}\text { Work shift: morning (7:00 a.m. to } 12: 59 \text { p.m), afternoon (1:00 p.m. to } 6: 59 \text { p.m), night } \\
\text { (7:00 p.m to 6:59 a.m.), or all) }\end{array}$ \\
\hline \multirow[t]{4}{*}{ Where } & Room 1, equipped with the 8-channel Ge CT, \\
\hline & Room 2, equipped with the 16-channel Philips CT, \\
\hline & Room 3, equipped with the 64-channel Toshiba CT, \\
\hline & or all rooms \\
\hline \multirow[t]{2}{*}{ Which? } & Individual choice of the code of the exam, \\
\hline & or all exam codes \\
\hline \multirow[t]{3}{*}{ What? } & ICA, in a $300 \mathrm{mg}$ lodine $/ \mathrm{mL}$ concentration, \\
\hline & ICA, in a 350 mg lodine/mL concentration, \\
\hline & or all concentrations \\
\hline \multirow[t]{3}{*}{ How? } & automated ICA injection using an injection pump, \\
\hline & manual ICA injection, \\
\hline & or all injections \\
\hline \multirow[t]{2}{*}{ Who? } & Individual choice using the code of the radiology technician, \\
\hline & or all radiology technicians \\
\hline
\end{tabular}

The upper-left quadrant of Figure 5 is highlighted, calling attention to the set of undesirable situations in this broad scenario. The definition of undesirable situation was obtained from a semi-directed interview with the managers. Finding the set of variables that contributes for these situations demands many analyses of the data set, carried out from different perspectives.

The result that better explains the undesired situations was obtained through a variation of the CT operator within this set of data. To explain this observation, Figures 6 and 7 show the same set of data, filtered to include only patients attended by Radiology technicians A and B, respectively. 
After data exploration, it was found that there is an excellent opportunity for the Service to improve the use of ICA volumes in the attention to patients with mass below $65 \mathrm{~kg}$. This finding became visible in Figure 5, in the highlighted upper-left side of the chart. It could also be noted that the processes of test execution have not been standardized within the Service and with the team, meaning that an effort to this end could make viable a diminution in the consumption of materials, especially for low-mass patients.

It can be noted that the use of simple consultations to databases and reports would not be capable to provide such a fast understanding of the behavior of the data. OLAP technology made it possible to work with many dimensions simultaneously, all of them before analysis. They were considered to be potential contributors for a greater consumption of material. The exploration of data with visual analysis from different perspectives made it possible to identify and prove, through data, whether there was a nonstandardized process in the Service, which led to the excessive use of materials.

In this section, there was an attempt to describe the most relevant discovery the investigation made with the data cube to support the decision-making process of the managers.

Planning, actions and controls defined considering evidences and their results

With the aid of the managers, the investigation continued in the database, seeking to identify the starting point that generated the highest financial and assistance impact. The decision about which exam should be conducted first, as a pilot, was based on data, using a strategy that resorted to the Pareto chart to answer the four defined questions together with the managers. The results are presented in the Table 3 below.

\section{Table 3 Support to decision making in the choice of the pilot exam, using the Pareto chart and considering the data cube}

\begin{tabular}{|c|c|c|c|c|c|}
\hline \multirow{2}{*}{$\begin{array}{l}\text { Questions of interest of the managers for } \\
\text { decision making, about where to start }\end{array}$} & \multicolumn{4}{|c|}{ Code of the exam } & \multirow[t]{2}{*}{ Sum } \\
\hline & TCAB1 & TCTX1 & TCCR1 & OUTROS & \\
\hline $\begin{array}{l}\text { 1. Among exams that use the ICA, which one } \\
\text { happens the most? }\end{array}$ & $39 \%$ & $25 \%$ & $7 \%$ & $29 \%$ & $100 \%$ \\
\hline $\begin{array}{l}\text { 2. Among exams that use the ICA in a } 300 \mathrm{mg} \\
\text { iodine } / \mathrm{mL} \text {, which one happens the most? }\end{array}$ & $47 \%$ & $31 \%$ & $7 \%$ & $15 \%$ & $100 \%$ \\
\hline $\begin{array}{l}\text { 3. Among exams that use the ICA, which one } \\
\text { uses the most volume of the material? }\end{array}$ & $42 \%$ & $26 \%$ & $5 \%$ & $27 \%$ & $100 \%$ \\
\hline $\begin{array}{l}\text { 4. Among exams that use the ICA, which one } \\
\text { uses the most volume of the material in a } 300 \\
\mathrm{mg} \text { iodine } / \mathrm{mL} \text { concentration? }\end{array}$ & $50 \%$ & $31 \%$ & $5 \%$ & $14 \%$ & $100 \%$ \\
\hline
\end{tabular}

TCAB1 (full CT scan of the abdomen), TCTX1 (CT scan of the thorax), and TCCR1 (CT scan of the skull/brain) 
It can be noted that the TCAB1 is the most representative, considering the four items analyzed. For that reason, it was chosen to be the pilot in the control of the waste of material. This was a strategic decision of the BI process applied towards a greater impact in clinical and financial results. Considering this databased decision, the planning, together with the managers, was structured in six groups of activity:

1. Reviewing the protocol of ICA injections in the exam selected to be the pilot;

2. Documenting the information thus generated;

3. Generating weekly automated controls;

4. Guiding the team;

5. Accompanying the data;

6. Assessing the clinical and financial impacts.

Performance of planned activities and results

The actions that put in practice the planning will be presented with the results of each activity and structured following the same order of organization.

Revision of the protocol of ICA injection about the exam chosen to be the pilot

The revision of the protocol of ICA injections for the TCAB1 exam was carried out during multiprofessional weekly meetings involving managers and representatives of the team of Radiology technicians, radiologists, nurses, and physicists. The preexisting guidance available for consultation in the last version of the protocol of exams in the CT unit, revised in January 2019 and referring to the protocol of ICA injections for the TCAB1 exam, was "Intravenous contrast: 1 to $2 \mathrm{~mL} / \mathrm{kg}$ (up to $150 \mathrm{ml}$ )".

This is an open orientation, leaving the final decision for the Radiology technician at the moment of the execution of the exam. As a result, there was an attempt to find the best association between the volumes injected and the imaging techniques available in the CT Scan, using as a reference the exams from the Service itself, which were evaluated with regard to their quality by the radiologists.

During the review, a strategic change in the protocol was decided. Its aim was to implement guidance with regard to the volume to be used for each concentration and corresponding mass range. Therefore, we tried to achieve a uniform choice of the volume to be injected in the patient and facilitate the decision of the operative team. Finally, a guiding table was formed (Table 4), which is presented below.

Documentation of the information generated

Table 4 shows the new guidance of the Radiology Service for the use of ICA in TCAB1 exams. 
Table 4 Protocol of ICA injection for TCAB1 exams containing the volume of reference according to mass range and concentration

\begin{tabular}{|lll|}
\hline Mass range of the patient & $300 \mathrm{mg}$ iodine $/ \mathrm{mL}$ & $350 \mathrm{mg}$ iodine $/ \mathrm{mL}$ \\
\hline up to $45 \mathrm{~kg}$ & $54 \mathrm{~mL}$ & $45 \mathrm{~mL}$ \\
\hline from $46 \mathrm{~kg}$ to $55 \mathrm{~kg}$ & $70 \mathrm{~mL}$ & $50 \mathrm{~mL}$ \\
\hline from $56 \mathrm{~kg}$ to $65 \mathrm{~kg}$ & $80 \mathrm{~mL}$ & $60 \mathrm{~mL}$ \\
\hline from $66 \mathrm{~kg}$ to $80 \mathrm{~kg}$ & $90 \mathrm{~mL}$ & $75 \mathrm{~mL}$ \\
\hline from $81 \mathrm{~kg}$ to $95 \mathrm{~kg}$ & $100 \mathrm{~mL}$ & $90 \mathrm{~mL}$ \\
\hline more than $96 \mathrm{~kg}$ & $110 \mathrm{~mL}$ & $100 \mathrm{~mL}$ \\
\hline
\end{tabular}

\section{Generation of weekly automated controls}

After the ICA injection protocol was defined for the exam of TCAB1, two control tools were developed using the interest variables of the multidimensional request-procedure model of Impax BI. The controls were generated in the form of a report and programmed to be automatically sent via email to the interested parties every Monday at 7 a.m. This was done using an agent, a resource available in the Impax $\mathrm{Bl}$, which contained all data from the exams from last week, with the period of evaluation lasting from Saturday to Friday.

\section{Team guidance}

After the protocol was reviewed, documenting the information and generation of automated controls, the supervisor of radiologic techniques provided guidance to the team of Radiology technicians in a meeting that involved workers from the three work shifts in a uniform manner, in the first week of the second quarter of December 2019. After this date, the operative team is expected to follow the new ICA injection protocol for all TCAB1 exams. The date in which the new protocol starts to be applied is an important milestone for the comparison of the effectiveness of the actions taken, making it possible to compare the scenario there was before the guidance in Table 4 was implemented to the one after its implementation.

\section{Data follow up}

Controls started to be sent to the managers and other interested parties who participated in this process in November 9, 2019. The creation of controls before the guidance of the operational team about the new process was important to motivate the team in the search for better results. Furthermore, the period before the guidance of the team about the new process was useful to carry out adjustments in the configuration of reports and data auditing, and from that moment on they started to be delivered with a guarantee that the information contained therein was correct. 
After the new ICA injection protocol for TCAB1 exams was in force, there was a diminution in the undesirable situations, above $2 \mathrm{~mL} / \mathrm{kg}$, related to the first control. Through the second control, it was possible to verify the standardization of the operational process with a uniformity in the work of the entire team, since the team effectively started to follow the new guidance of ICA injections prescribed by the Service. The strategy of result follow up, with information from the previous week, made it possible for managers to trace actions to intervene, when necessary, in recent occurrences.

\section{Evaluation of clinical and financial impacts}

The BI process applied generated clinical and financial impacts that could be perceived and measured. The clinical impacts are shown in Figure 8, where data from the periods $A$ and $B$ are compared, respectively corresponding to the scenarios before and after the ICA injection protocol for TCAB1 exams was changed.

In period B, there was a standardization of the ICA injection volumes according to the mass of the patient, and the attention process for the exam analyzed was more uniform than in period $A$.

The clinical gains become more perceptible in the analysis of the mean ICA volume injected per exam in a certain monthly period when the sample varies according to the age group of the patient. Comparative charts presented in Figure 9 were generated to evidence a diminution in the mean ICA volume injected in the different mass ranges of the patient. The horizontal line in each of the charts indicates the reference value defined in Table 4. The comparison was obtained through the OLAP slice operation, which was applied to the different mass ranges of patients in the data sample selected for analysis. It was found that the ICA volume diminished in all mass ranges, especially for patients below $65 \mathrm{~kg}$.

A projection was also calculated to predict the financial impact of the actions taken after the implantation of the BI process. It adopted, as a reference, the data cube used in the investigative dashboard. Using it, it was possible to evaluate the economic result generated from the definitions of the ICA injection protocol for the TCAB1 exam, due to its clarity in the guidance and standardization of operational processes. To do so, an analysis was carried out that included two distinct 12 month periods from the data cube, as shown in Table 5.

\section{Table 5 Assessment of the financial impacts for TCAB1 exams}




\begin{tabular}{|c|c|c|c|c|}
\hline Information about the measurement & $\begin{array}{l}07 / 01 / 2017 \\
\text { to } \\
06 / 30 / 2018\end{array}$ & $\begin{array}{l}07 / 01 / 2018 \\
\text { to } \\
06 / 30 / 2019\end{array}$ & $\begin{array}{l}\text { Annual } \\
\text { mean }\end{array}$ & $\begin{array}{l}\text { Sum } \\
\text { (24 } \\
\text { months) }\end{array}$ \\
\hline Total volume used & $719,898 \mathrm{~mL}$ & $705,699 \mathrm{~mL}$ & $\begin{array}{l}\text { 712,799 } \\
\mathrm{mL}\end{array}$ & $\begin{array}{l}1,425,597 \\
\mathrm{~mL}\end{array}$ \\
\hline $\begin{array}{l}\text { Volume that could have been used } \\
\text { considering the new ICA injection } \\
\text { protocol }\end{array}$ & $602,638 \mathrm{~mL}$ & $599,850 \mathrm{~mL}$ & $\begin{array}{l}601,244 \\
\mathrm{~mL}\end{array}$ & $\begin{array}{l}1,202,488 \\
m L\end{array}$ \\
\hline Excessive volume used & $117,260 \mathrm{~mL}$ & $105,849 \mathrm{~mL}$ & $\begin{array}{l}111,555 \\
\mathrm{~mL}\end{array}$ & $\begin{array}{l}223,109 \\
\mathrm{~mL}\end{array}$ \\
\hline Value of the excess & $\begin{array}{l}\text { US\$ } \\
10,553.40\end{array}$ & US\$ 9,526.41 & $\begin{array}{l}\text { US\$ } \\
10,039.95\end{array}$ & $\begin{array}{l}\text { US\$ } \\
20,079.81\end{array}$ \\
\hline
\end{tabular}

The value used to calculate the projection is based on the last public notice in the electronic bidding model carried out by the HCPA to acquire ICA. The cost of each $\mathrm{mL}$ of $300 \mathrm{mg}$ iodine/ $\mathrm{mL}$ concentration ICA is of US\$ 0.09 .

The difference between the volume used and the standardized volume was of $15.65 \%$, considering only the TCAB1 exam. Therefore, the projection predicted savings of US\$10,039.95 per year from 2020 on, in the cost of ICA at the HCPA, considering the mean of the 24 previous months used for this pilot exam. This is the cost of the excessive volume projected to be wasted in one year if the BI project had not been implemented. This result, from 2020 on, contributes directly for the sectoral indicator "revenue commited for consumption", which measures the ratio of total financial revenue of the service to all financial values used to pay materials consumed in the corresponding period.

\section{Assessment of the perception of managers about the process applied}

To carry out a quantitative evaluation about the impact and relevance of the BI process applied in the HCPA, a semi-directed interview was elaborated with the management, based on the Marconi and Lakatos (2010) methodology, as a way to measure the results achieved.

The interviews were previously scheduled with the same five managers who participated in the first semidirected interview at the beginning of the work. The meetings were carried out individually through a web conference, which lasted for a mean of one hour. This period was divided in two stages.

In the first stage, the objectives of the work and of the interview were presented to the managers, as well as the research question and the business question of the investigation, its results and its conclusion. In this stage, a report was carried out about the activities developed in the BI process applied, seeking to elucidate the values reached for the business in clinical and financial terms.

In the second stage of the interview, 10 questions were asked, which had been elaborated by the authors of this work. Their answers were in a scale from 0 to 5 , and they aimed to quantify the impact and the 
relevance of each question, where 0 was low and 5 was high. NA meant "does not apply" that is, the dimension was not within the perspective considered by the interviewee. Finally, a mean percentage of the impact and relevance of each question was found. Results are in the Table 6 below.

\section{Table 6 Impact and relevance in the perception of the managers about the BI process as applied in the HCPA}

\begin{tabular}{|c|c|}
\hline $\mathrm{BI}$ process applied in the HCPA & $\begin{array}{l}\text { Mean percentage of the impact and } \\
\text { relevance in the perception of the managers } \\
(\%)\end{array}$ \\
\hline Was the result presented satisfactory? & $100 \%$ \\
\hline Was it important to identify the waste of ICA? & $100 \%$ \\
\hline $\begin{array}{l}\text { Was it important to give support to the decision } \\
\text { making process? }\end{array}$ & $96 \%$ \\
\hline $\begin{array}{l}\text { Did it help in the planning of actions and in the } \\
\text { definition of controls from the evidence generated? }\end{array}$ & $100 \%$ \\
\hline Did it help in the control of undesirable situations? & \multirow[t]{3}{*}{$100 \%$} \\
\hline - ICA injections with values above $2 \mathrm{~mL} / \mathrm{kg}$. & \\
\hline $\begin{array}{l}\text { - Injections above the reference value indicated in the } \\
\text { ICA injection protocol for the TCAB1 exam }\end{array}$ & \\
\hline Did it enable a better management of ICA use? & $100 \%$ \\
\hline Did it generate a satisfactory financial result? & $100 \%$ \\
\hline Did it generate benefits for the patients? & $100 \%$ \\
\hline $\begin{array}{l}\text { Was it decisive for the follow up of operational } \\
\text { routines? }\end{array}$ & $100 \%$ \\
\hline Should it continue to be used? & $100 \%$ \\
\hline
\end{tabular}

One of the interviewees indicated, in the interview, an additional item, which was classified as having $100 \%$ of impact and relevance, which was the extinction of the divergences between the teams of Nursing technicians and Radiology technicians about the volume of ICA that should be injected in the patient. Furthermore, the standardization helped the preparation of the ICA injection pump to be faster, since the volume, now, was predefined.

The general score obtained was of $99.6 \%$ of impact and relevance in the perception of the interviewees, with regard to the BI process applied to the HCPA. This value was obtained through a mean between all questions answered by the five interviewees.

\section{Conclusion}


Motivated by the constant need of adopting better health management instruments, this work showed that BI technologies can be successfully applied to avoid situations of ICA waste in CT units. With the use of OLAP operations applied to an investigative dashboard to explore a data cube with the managers, it was found in which situations there was an excessive use of the material. The discovery was made when it was found that the Radiology technician influenced the behavior of the curve in the ICA volume/mass ratio injected in the patient. Using this evidence, and based on the data, it was found that the process of defining the volume of ICA injection by the Radiology technician was not standardized.

The strategy, created as part of the BI process, involved a multiprofessional team formed by managers and representatives of the teams of Radiology technicians, radiologists, nurses, and physicists to revise the guidance of the protocol of injection of ICA for the TCAB1 exam, which was the pilot. The open guidance was restructured into a restricted model, according to the mass range of the patient. The creation of two automated controls with structured weekly reports that were sent via email to the interested parties allowed for the data monitoring and the intervention of the managers when needed.

The clinical gains were more expressive for patients with a low mass (below $65 \mathrm{~kg}$ ); however, the adjustment of the use of the material to the needs of the patients took place for all mass ranges, which now counted on the indication provided by standardized ICA volumes. The financial gains were the consequence of the adjustment carried out considering the clinical needs of diagnostic confirmation in exams that use the ICA. The first exam to be revised by the ICA injection protocol was chosen according to data analysis, with the objective of having a greater impact, and therefore, a decision was made to analyze the TCAB1.

The diminution in the waste of materials due to excessive use brought financial gains to the business. These gains were estimated comparing a historic database of 24 months and the new guidance of the ICA injection protocol for the TCAB1 exam. For this exam, projections indicated a reduction of $15.65 \%$ in the use of the material, reflecting in a US\$10,039.95 diminution in expenses per year, starting from the year 2020.

This work enabled a better managing of the use of ICA, bringing gains from two fundamental perspectives: one of them related to the clinical effects of using lower volumes of contrast, such as a diminution of the nephrotoxicity of the ICA and the lower risk of circulatory overload of the patients, and another from the financial perspective, regarding the efficiency in the use of resources. The perception about the BI process applied to the HCPA was measured through semi-directed interviews responded by the five managers, which obtained a final mean result of $99.6 \%$ of impact and relevance, from the point of view of the interviewees.

As a result, the methodological proposal of this work generated an evaluation process capable of producing knowledge with a positive impact, which can be shared with other public or private health organizations. Support was given to the decision-making process of managers, giving base to plans, actions, and controls that favored the business. Its result was an evaluation with a high percentage of impact and relevance, according to the perception of the managers of the application of the BI process. 


\section{Declarations}

\section{Ethics approval and consent to participate}

Ethical Approval: Formal ethics approval has been waived.

Informed Consent: The need for consent has been waived.

The need for ethics approval was considered unnecessary since the research did not fall under the terms of Brazilian Resolution No. 466, of December 12, 2012, of the National Health Council and of Brazilian Law No. 11,794, of October 8, 2008, which regulate the Research Ethics Committee and the National Research Ethics Commission. This study was submitted to the Research Committee of the Universidade Federal de Ciências da Saúde de Porto Alegre and registered under number 004/2019. As the data used in this study are related to the types of exams and related resources, there is no risk regarding the identification of the patients involved and, therefore, there are no implications regarding ethical issues. The authors declare that all methods were carried out in accordance with the relevant guidelines and regulations.

\section{Consent for publication}

Not applicable.

\section{Availability of data and materials}

All data generated or analysed during this study are included in this published article.

\section{Competing interests}

The authors declare that they have no competing interests.

\section{Funding}

No funding was used to support this study.

\section{Authors'Contributions}

JA was involved in the performance of the study, data analysis and interpretation, as well as in the writing of the manuscript. LB supervised and guided the study and contributed for data interpretation. The authors carried out critical revisions of the manuscript, offering important contributions to its intellectual content. The authors read and approved the final version of this article.

\section{Acknowledgements}

We are grateful to the Radiology Service and the Medical Physics Service of Hospital de Clínicas de Porto alegre for granting access to their data, and for their expertise and time. 


\section{About the author}

1Post-graduation Program in Technologies of Health Information and Management, Universidade Federal de Ciências da Saúde de Porto Alegre, Rio Grande do Sul, BR.

\section{References}

1. Controladoria-Geral da União (CGU). Saúde. Portal da transparência, 2019. http://www.portaltransparencia.gov.br/funcoes/10-saude?ano=2019. Accessed 22 Apr 2019.

2. Kodzwa R. ACR Manual on Contrast Media: 2018 Updates. Radiol Technol. setembro de 2019;911:97-100.

3. Juchem BC, Almeida M de A. Risk for adverse reaction to iodinated contrast media: a validation study. 2017;38:e68449.

4. Juchem BC, Dall'Agnol CM. Immediate adverse reactions to intravenous iodinated contrast media in computed tomography. Rev lat-am enferm. 2007;15:78-83.

5. Nagy PG, Warnock MJ, Daly M, Toland C, Meenan CD, Mezrich RS. Informatics in radiology: automated Web-based graphical dashboard for radiology operational business intelligence. Radiographics. novembro de 2009;29:1897-906.

6. Prevedello LM, Andriole KP, Hanson R, Kelly P, Khorasani R. Business Intelligence Tools for Radiology: Creating a Prototype Model Using Open-Source Tools. J Digit Imaging. $1^{\circ}$ de abril de 2010;23:13341.

7. Liu Y, Yu H, Li J. Data Mining of Inspection-Time Rules in HIS with DeepSee. 2nd International Workshop on Database Technology and Applications, Wuhan; 2010. doi: 10.1109/DBTA.2010.5658940.

8. Jones S, Cournane S, Sheehy N, Hederman L. A Business Analytics Software Tool for Monitoring and Predicting Radiology Throughput Performance. J Digit Imaging. 2016;29:645-53.

9. Sigler R, Morrison J, Moriarity AK. The Importance of Data Analytics and Business Intelligence for Radiologists. J Am Coll Radiol. abril de 2020;17:511-4.

10. Marconi, MA, Lakatos EM. Fundamentos de Metodologia Científica. 7th ed. São Paulo: Atlas; 2010.

\section{Figures}




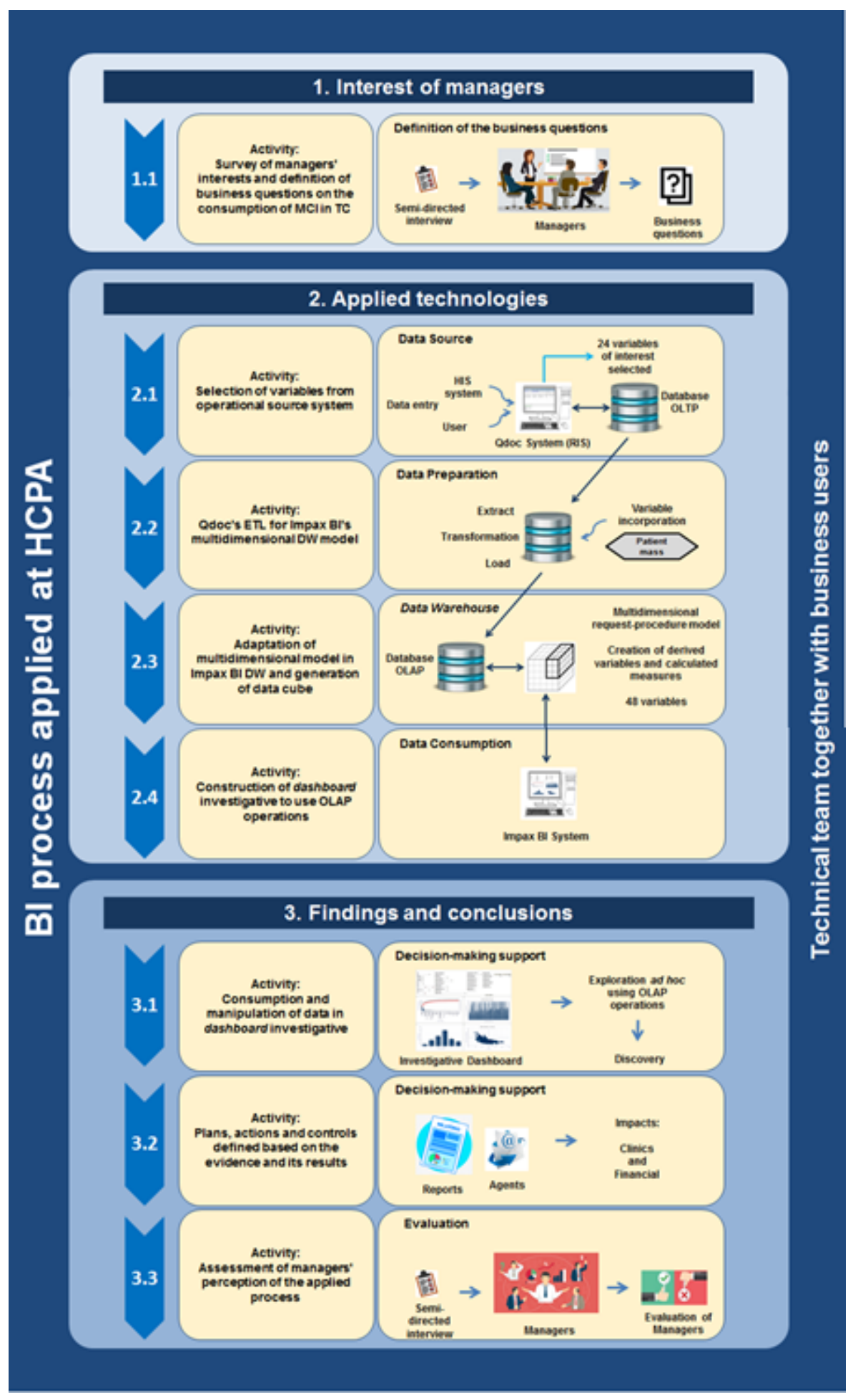

Figure 1

BI process applied in the HCPA 


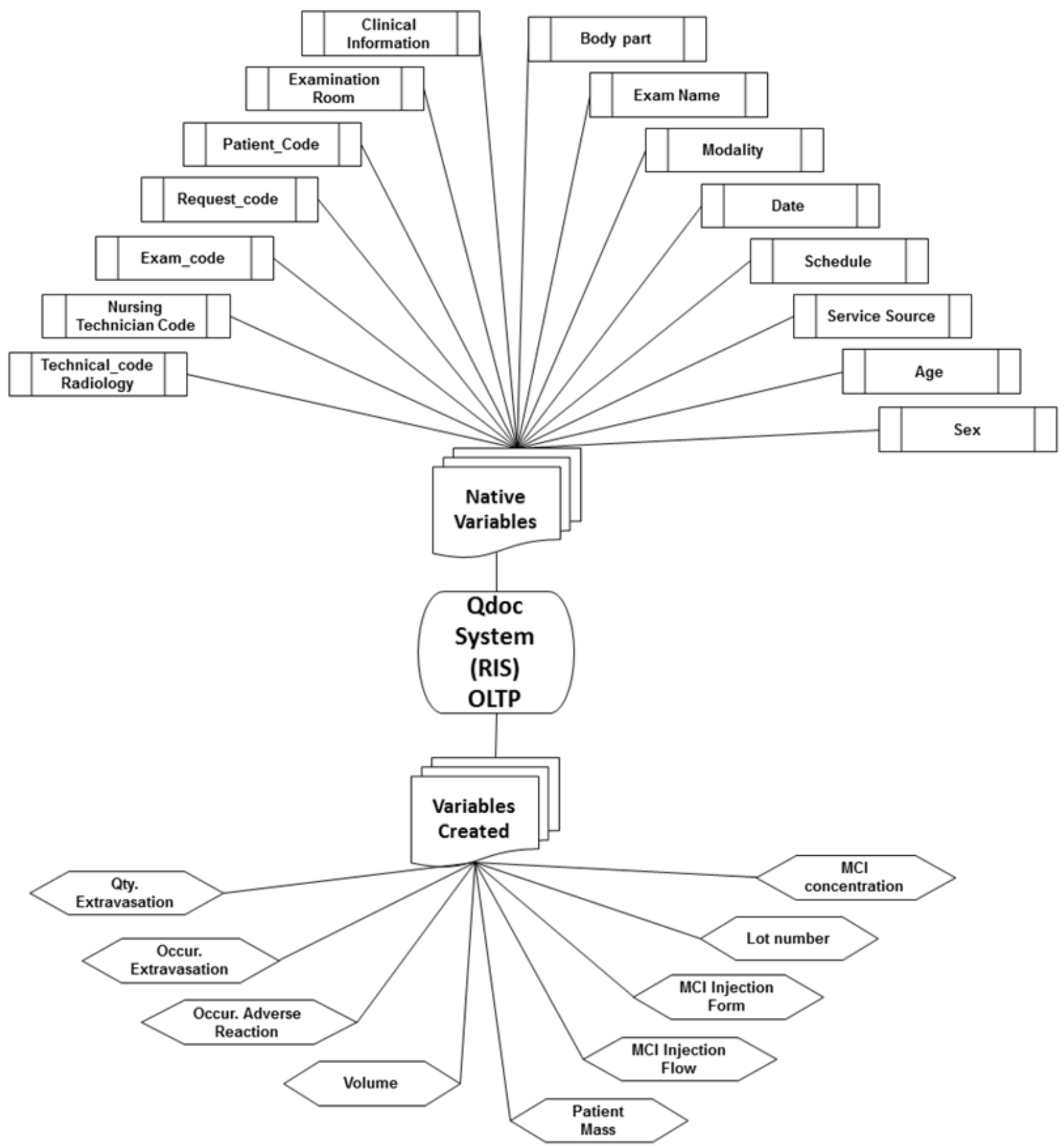

Figure 2

Form of existence of the variables in the Qdoc system: native and created 


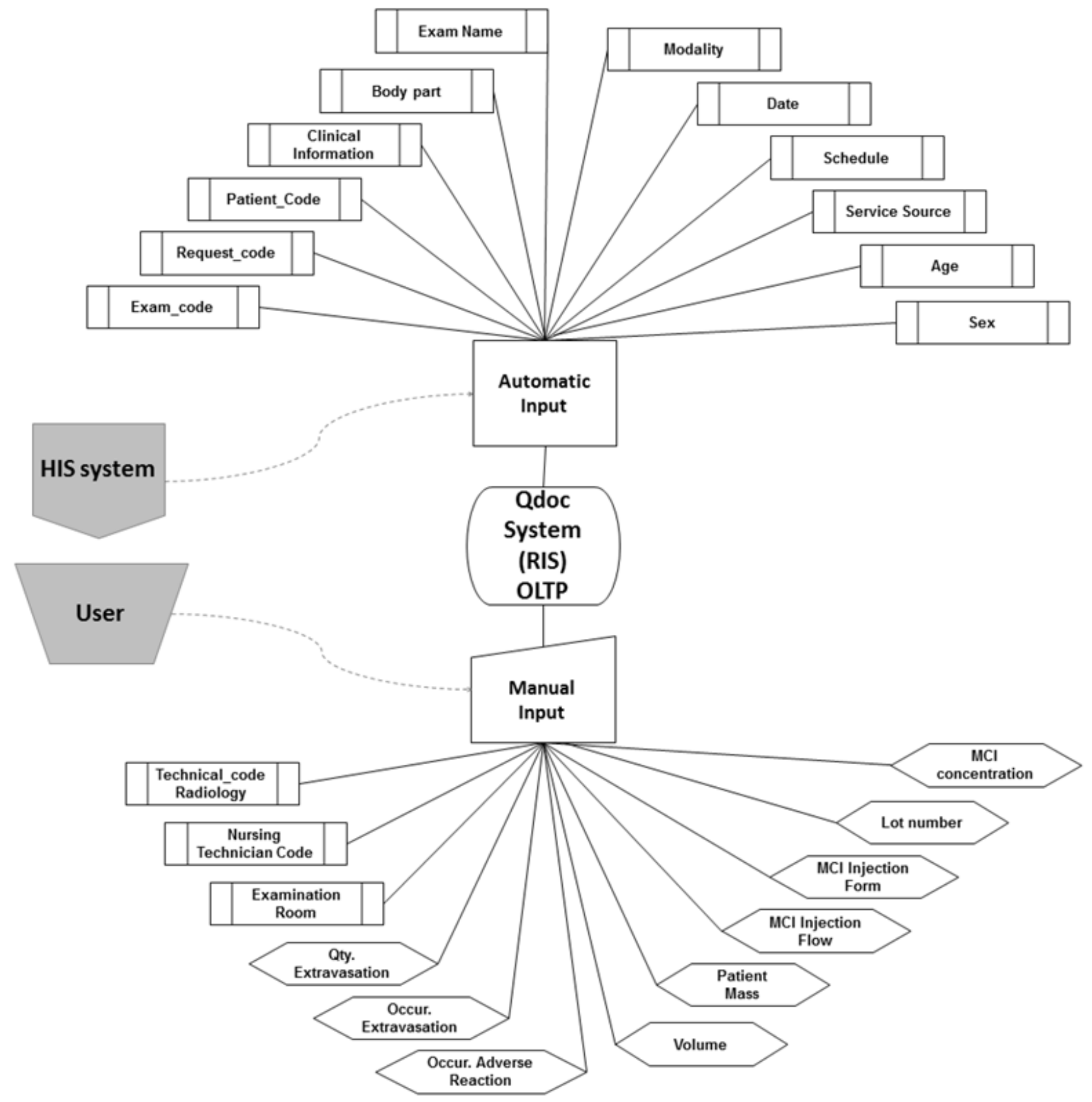

Figure 3

Form of input of variables in the Qdoc system: automatic or manual input 


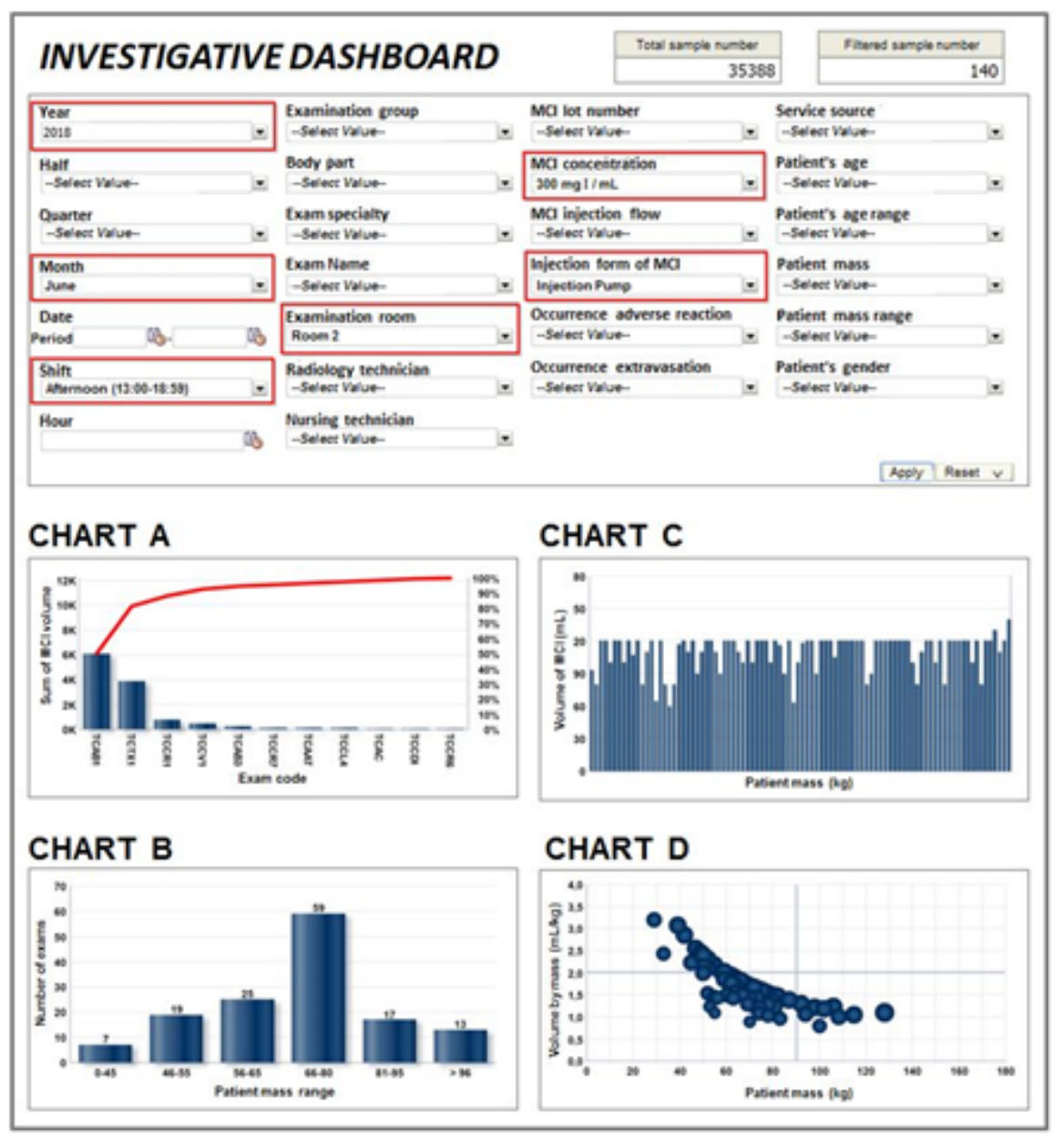

Figure 4

Proposal of an investigative dashboard to answer to the business question using OLAP operations with an example of an analysis from four perspectives

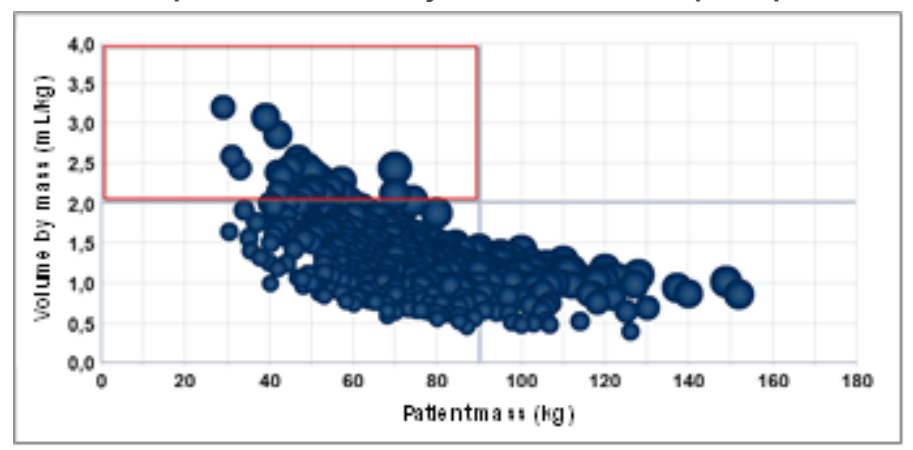

Figure 5

Ratio of ICA volume injected to patient mass in the HCPA Radiology Service in June 2018, with highlights on the quadrant of undesirable situations 


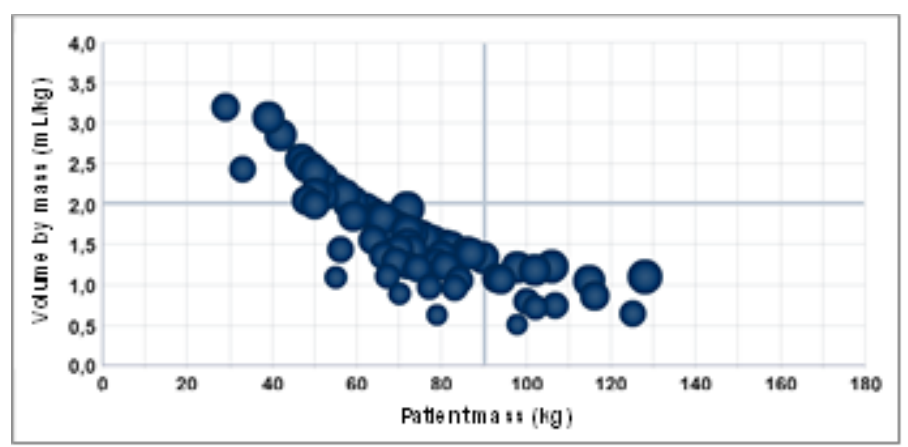

Figure 6

Ratio of ICA volume injected to patient mass in the HCPA Radiology Service in June 2018, by Radiology technician A

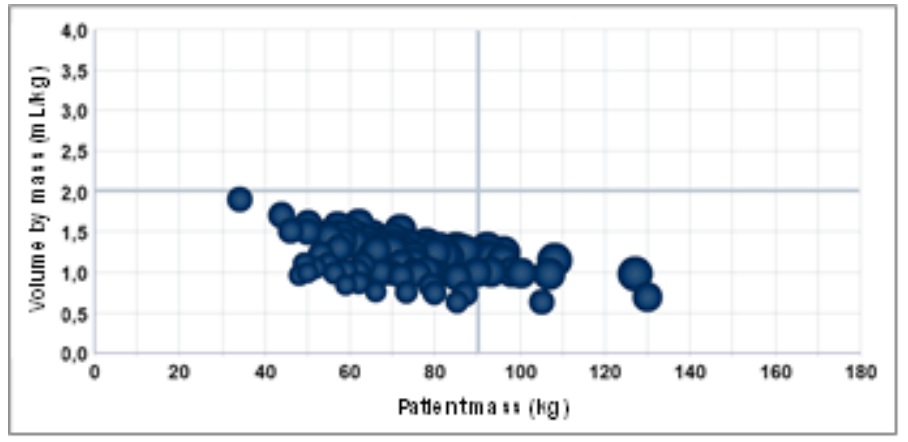

Figure 7

Ratio of ICA volume injected to patient mass in the HCPA Radiology Service in June 2018, by Radiology technician B

\section{Period A: March 2018}

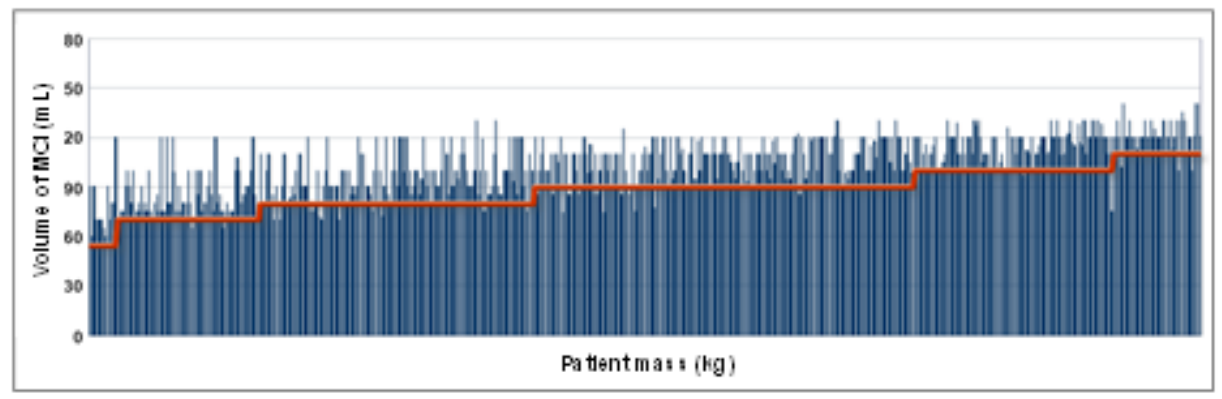

\section{Period B: March 2020}

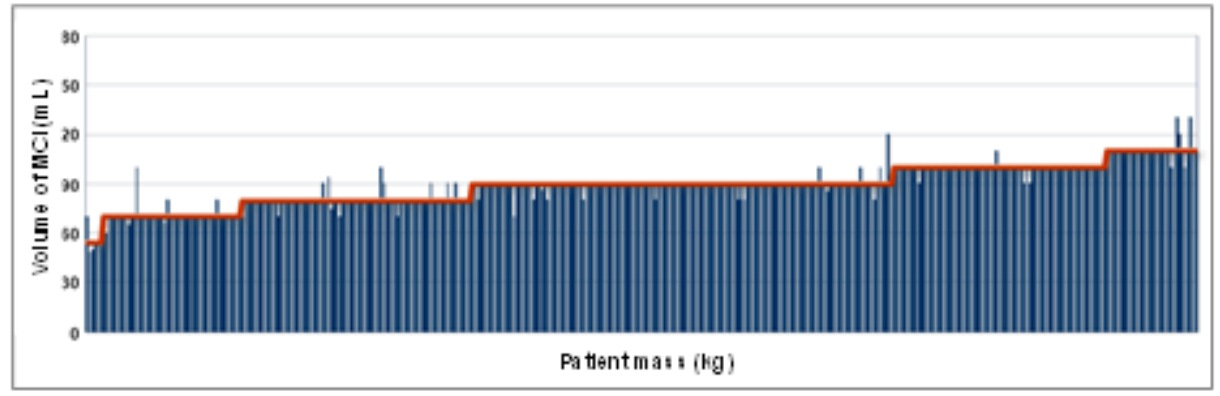


Figure 8

Comparison of data in the periods $A$ and $B$, respectively corresponding to the scenarios before and after the ICA injection protocol for TCAB1 exams was changed

Group of patients A: mass range from $46 \mathrm{~kg}$ to $55 \mathrm{~kg}$

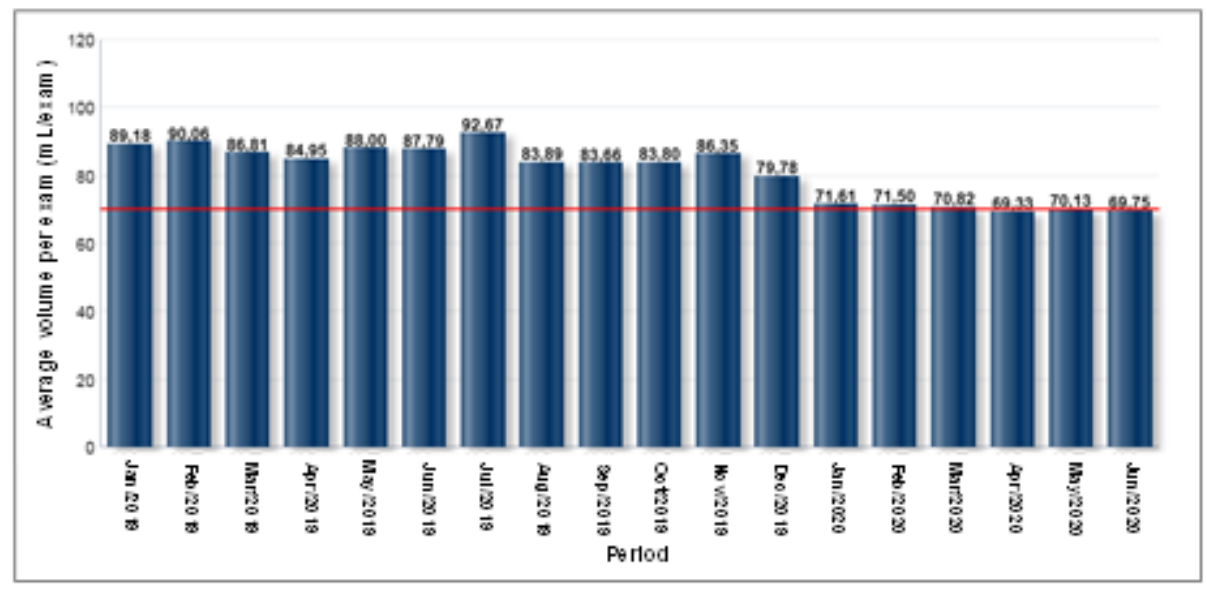

Group of patients B: mass range from $81 \mathrm{~kg}$ to $95 \mathrm{~kg}$

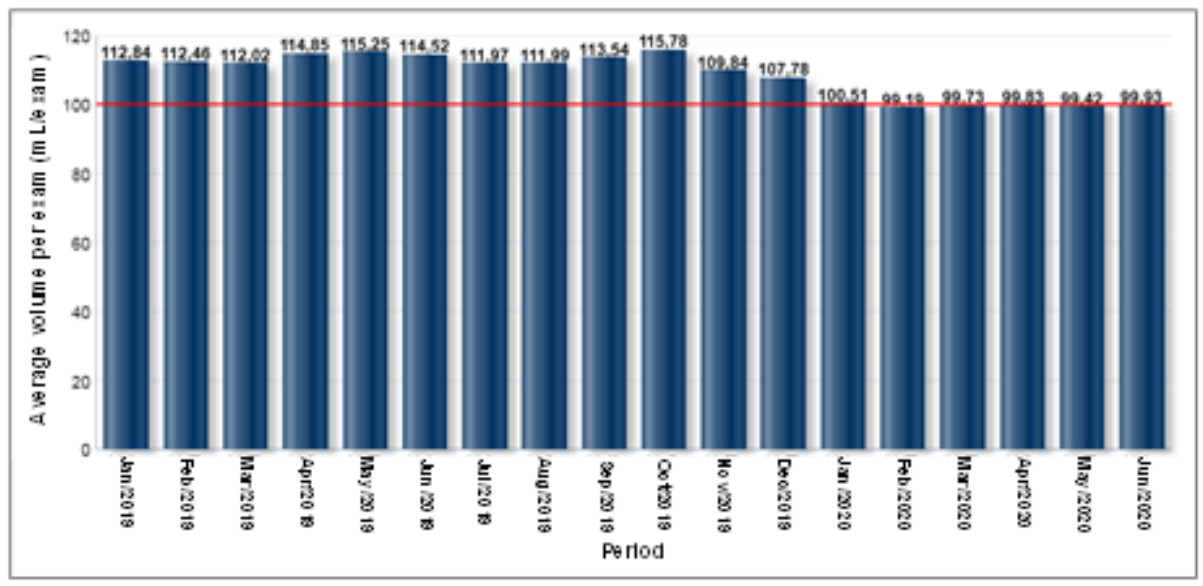

Figure 9

Comparison of the data about the volume of ICA per patient mass range for the TCAB1 exam using ICA in a $300 \mathrm{mg}$ iodine $/ \mathrm{mL}$ concentration 